\title{
Preclinical formulation for the pharmacokinetics and efficacy of GBO-006, a selective polo like kinase 2 (PLK2) inhibitor for the treatment of triple negative breast cancer
}

Srinivas Maddi ${ }^{1}$, Ravi Akkireddy ${ }^{1}$, Srinivas Lenkalapelly ${ }^{1}$, Pratima Srivastava ${ }^{1}$, Joshodeep Boruwa ${ }^{1}$, Chandra Deb ${ }^{1}$, Arnab Roy Chowdhury ${ }^{1}$, Duraiswamy A. Jeyaraj ${ }^{1}$, Ramana Reddy ${ }^{2}$, Premkumar Reddy ${ }^{3}$, Manoj Maniar ${ }^{4}$, Sachin Bansal ${ }^{5}$ and Jang B. Gupta $^{1}$

${ }^{1}$ GVK Biosciences PVT LTD., Nacharam, Hyderabad 500076, India

${ }^{2}$ Department of Structural and Chemical Biology, Mount Sinai School of Medicine, New York, NY 10029

${ }^{3}$ Department of Oncological Sciences, Mount Sinai School of Medicine, New York, NY 10029

${ }^{4}$ Onconova Therapeutics, Newtown, PA 18940

${ }^{5} 5 A S B$ life sciences PVT LTD., Nacharam, Hyderabad 500076, India

*Corresponding Author: Email: srinivasarao.maddi@gvkbio.com;_tel: 919701166299.

Received: September 23, 2016; Revised: December 13, 2016; Published: December 26, 2016

\begin{abstract}
GBO-006 was shown to be a highly specific and selective PLK2 inhibitor that promoted mitotic arrest in various cancer cell lines, subsequently resulting in their apoptotic death. Intraperitoneal alternate day dosing of GBO-006 using $100 \%$ DMSO as formulation showed significant tumor regression in xenograft models, demonstrating proof of concept of PLK2 inhibition in vivo. These studies necessitated the development of a suitable and GRAS (generally considered as safe) preformulation for pharmacokinetic and efficacy studies. GBO-006 possesses challenging physicochemical and biopharmaceutical properties like poor solubility in aqueous media, low permeability and a crystalline nature. Different methods like cosolvency, complexation and micellar solubilization were employed to improve the solubility of GBO-006. A strategy of co-solvency is used to solubilize the GBO-006 up to $10 \mathrm{mg} / \mathrm{mL}$. A formulation with $20 \%$ DMSO, $40 \%$ PEG 400, $30 \%$ of $100 \mathrm{mM}$ citrate buffer (pH 3.0) and $10 \%$ solutol displayed clear solution without any visual precipitation of the drug even after 2 weeks of storage. GBO-006 showed moderate clearance in rat and high systemic clearance in mouse and dog. It showed poor oral bioavailability across all species. Intraperitoneal dosing of GBO-006 demonstrated the linear exposure. GBO-006 showed significant inhibition of tumor progression.
\end{abstract}

\section{Keywords}

GBO-006; PLK2 inhibitor; Pharmacokinetics; Efficacy; Triple negative breast cancer

\section{Introduction}

The up regulation of Polo like kinase PLK1 plays a key role in mitosis but little is known about the oncogenic significance of PLK2 [1-2]. PLK2 kinase activity is essential for centriolar duplication and is also believed to play a regulatory role in the survival pathway [3-5]. Protein tyrosine hyper-phosphorylation and the up regulation of serine/threonine kinases associated with cell cycle progression have been linked to the 
etiology of cancer. In our attempt to develop ATP-mimetic compounds that are cytotoxic against a panel of cancer cell lines, we identified several sulfonyl pyridopyrimidines that exhibit cyto-toxicity at nanomolar concentrations [6-8]. The most potent of these compounds, GBO-006 (2-(1H-indol-5-ylamino)-6-(2,4difluorophenylsulfonyl)-8-methylpyrido[2,3-d]pyrimidin-7(8H)-one) was found to be a specific PLK2 inhibitor when profiled against a panel of 288 wild-type, 55 mutant and 12 special kinases. In vitro testing revealed that GBO-006 was found to be PLK2 specific and selective inhibitor with nanomolar potency and no inhibitory activity against PLK1, PLK3 and PLK4. The cytotoxic effect of the drug is mediated by apoptosis as evidenced by the induction of caspase $3 / 7$ activity and by the cleavage of PARP in a dose dependent manner [9]. It affects cell cycle progression by blocking tumor cells in the G2/M phase. Intraperitoneal alternate day dosing of GBO-006 using $100 \%$ DMSO as formulation lead to significant tumor regression in Xenograft models, demonstrating proof of concept of PLK2 inhibition in vivo. However, GBO-006 showed poor solubility in aqueous media $(<0.1 \mu \mathrm{g} / \mathrm{mL})$, had a low permeability and a crystalline nature, making it very hard to have a feasible formulation with moderate concentration, prompting studies to develop a preclinical formulation. In this paper, we have presented the use of co-solvent based formulation to increase the solubility of the compound. The developed formulation was subsequently used to perform pharmacokinetic studies (mice, rats and dogs) and efficacy studies, with GBO-006 as a single agent in SCID Beige mouse xenograft models.

\section{Materials and methods}

\section{Chemicals and reagents}

GBO-006 was synthesized with the purity of $99.5 \%$ in-house (GVK biosciences Pvt. Ltd, Hyderabad, India). All co-solvents, surfactants, solutol, glycerin, complexing agents, lipids and oils were purchased from Sigma-Aldrich (St. Louis, USA). Liquid chromatography grade acetonitrile, methanol and ethanol were purchased from E. Merck Limited (Mumbai, India). Multi-screen solvinert inert filter plates $(0.45 \mu \mathrm{M}$, low binding hydrophilic PTFE) were purchased from Millipore. All aqueous solutions were prepared in Mili-Q water (Millipore, MA). All other chemicals were of analytical grade. Matrigel was procured from SigmaAldrich (DLW356235).

\section{Solubility studies}

Solubilization approach using co-solvent(s) and surfactant(s) were tried to optimize the best formulation for pharmacokinetic and efficacy studies. To estimate solubility qualitatively, known amount of GBO-006 was taken in clear glass vial. To this, known volume of test media was added and observed for clarity. GBO006 was dissolved in nearly $30-80 \%$ of mixtures of co-solvents with the aid of heating and bath sonication as and when required. Aqueous medium was added only if solution was obtained in co-solvents. Aqueous medium consisted of solution of anti-nucleating polymer and/or surfactant in distilled water or buffer. If required, sample was intermittently bath sonicated and heated at $60-80^{\circ} \mathrm{C}$. Test media was added either till a solution was obtained or till theoretical concentration was achieved (data not shown). The final sample was observed both visually and also by using polarized light microscopy for better clarity (in terms of number of visible particles).

\section{Pharmacokinetics}

\section{Pharmacokinetics in rats}

Male Sprague Dawley (SD) rats weighing 240-260 g were obtained from the taconic laboratories (Vivo biotech, Hyderabad, India). They were housed under standard conditions and were maintained under a $12 \mathrm{~h}$ light/dark cycle in the laboratory animal resources facilities, GVK Biosciences Pvt. Ltd, Hyderabad, India 
(AAALAC accredited). They were allowed access to commercial rodent chow and water ad libitum. Rats were fasted overnight before dosing and then until $3 \mathrm{~h}$ after dosing. Water was allowed ad libitum during the fasting period. Rats were cannulated at the jugular vein for serial bleeding. Three male rats per group were dosed via oral (PO, $5 \mathrm{mg} / \mathrm{kg}$ ) and intravenous (IV, $1 \mathrm{mg} / \mathrm{kg}$ ) routes for the determination of pharmacokinetics of GBO-006. After dosing, $0.3 \mathrm{ml}$ specimens of blood were collected by serial sampling from the jugular cannula at 0.25, 0.5, 1, 2, 4, 8 and $24 \mathrm{~h}$ after PO, and 0.08, 0.25, 0.5, 1, 2, 4, 8, $24 \mathrm{~h}$ after IV route, respectively. After collection, blood was processed to plasma by centrifugation at $10000 \mathrm{rpm}$ for 5 min, and samples were analyzed by LC-MS/MS.

\section{Pharmacokinetics in mice}

Swiss albino mice were obtained from taconic Laboratories (Vivo biotech, Hyderabad, India). They were housed under standard conditions and were maintained under a $12 \mathrm{~h}$ light/dark cycle in the laboratory animal resources facilities, GVK Biosciences Pvt. Ltd, Hyderabad, India (AAALAC accredited). They were allowed access to commercial rodent chow and water ad libitum. Mice were fasted overnight before dosing and then until $3 \mathrm{~h}$ after dosing. Water was allowed ad libitum during the fasting period. The bodyweights of individual mice, ranging from 25 to $30 \mathrm{~g}$, were determined on the morning of the study. Nine mice for oral route and twelve mice for i.v. route were dosed. After dosing, $0.1 \mathrm{ml}$ specimens of blood were collected by stagger sampling with two bleeds per mouse from the retro orbital plexus at $0.5,1,2,4,8,24 \mathrm{~h}$ after PO route and $0.08,0.25,0.5,1,2,4,8,24 \mathrm{~h}$ after IV route respectively. After collection, blood was processed to plasma by centrifugation at $10000 \mathrm{rpm}$ for $5 \mathrm{~min}$, and samples were analyzed by LC-MS/MS.

\section{Dose dependent intraperitoneal pharmacokinetics in mice}

GBO-006 was administered in mice via IP route at $10,30,75$ and $100 \mathrm{mg} / \mathrm{kg}$ dose to understand the dose dependent exposure. After dosing, $0.3 \mathrm{ml}$ specimens of blood were collected by stagger sampling with two bleeds per mouse from the retro orbital plexus at 0.5, 1, 2, 4, 8, $24 \mathrm{~h}$. Blood was processed for plasma collection by the process mentioned in the above pharmacokinetics section.

\section{Pharmacokinetics in dogs}

Dog studies were performed at Palamur Biosciences Pvt. Ltd (Hyderabad, India). Six male Beagle dogs were housed under standard conditions and were maintained under a $12 \mathrm{~h}$ light/dark cycle in the laboratory animal resources facilities. They were allowed access to water ad libitum. Dogs were fasted overnight before PO dosing and then until $4 \mathrm{~h}$ after dosing. Water was allowed during the fasting period. The body weight of the individual dogs ranged from 9.6 to $14.3 \mathrm{~kg}$. Three male dogs per group were dosed per oral (PO), intravenous (IV) at 5 and $1 \mathrm{mg} / \mathrm{kg}$ for the determination of pharmacokinetics of GBO-006. After dosing, $0.3 \mathrm{ml}$ specimens of blood were collected by serial sampling from the saphenous vein at $0.167,0.5,1,2,4,8,12,24 \mathrm{~h}$ after PO route and $0.033,0.167,0.5,1,2,4,8,12,24 \mathrm{~h}$ after IV route, respectively. After collection, blood was processed to plasma by centrifugation at $10000 \mathrm{rpm}$ for $5 \mathrm{~min}$, and samples were analyzed by LC-MS/MS.

\section{Liquid chromatography - mass spectrometry analysis}

In vivo samples were prepared by protein precipitation with the addition of $200 \mu \mathrm{L}$ acetonitrile containing internal standard (telmisartan; $200 \mathrm{ng} / \mathrm{mL}$ ) to $25 \mu \mathrm{L}$ sample volume. Samples were vortexed and centrifuged at $4000 \mathrm{rpm}$ for $10 \mathrm{~min}$. Then $100 \mu \mathrm{L}$ of supernatant was diluted with $100 \mu \mathrm{L}$ of methanol: water mixture vortexed and injected for analysis. Standard and quality control samples were prepared by adding $1 \mu \mathrm{L}$ of aqueous known standard / quality control samples to $24 \mu \mathrm{L}$ of blank plasma and processed as mentioned above. The selected $[\mathrm{M}+\mathrm{H}]^{+}$and product ions monitored were $\mathrm{m} / \mathrm{z} 468.2,290.2$ for GBO-006 
(Figure 1) and $\mathrm{m} / \mathrm{z} 515.3,276.1$ for telmisartan, respectively. The high-performance liquid chromatography column was a C18-XBridge column $(4.6 \times 50 \mathrm{~mm}, 3.5 \mu \mathrm{m})$ maintained at $400 \mathrm{C}$ with a flow rate of $1.0 \mathrm{~mL} / \mathrm{min}$ with the split ratio of $60: 40$. The mobile phase consisted of $0.1 \%$ formic acid $(A)$ and methanol (B). The initial mobile phase composition was $80 \% \mathrm{~A} / 20 \% \mathrm{~B}$ and continued until $1.0 \mathrm{~min}$, then it was changed to $5 \%$ A/95\% B over 2.1 minutes. After $2.1 \mathrm{~min}$, the mobile phase is slowly shifted to $80 \% \mathrm{~A} / 20 \%$ B by $2.2 \mathrm{~min}$ following which it was held at same for 3.2 minutes. The high performance liquid chromatography (HPLC) was interfaced to API 4000 (AB Sciex, CA) mass spectrometer operated in the positive ion electrospray with multiple reaction monitoring (MRM) mode. The peak area ratio of analyte to internal standard was plotted against analyte concentrations, and the standard curve and was fitted by weighted $\left(1 / \mathrm{X}^{2}\right)$ least-squares linear regression in the concentration ranged from 1 to $1000 \mathrm{ng} / \mathrm{mL}$. A correlation of 0.995 was desirable for the calibration curve. The limit of quantitation for the purposes of this assay was $1 \mathrm{ng} / \mathrm{mL}$.

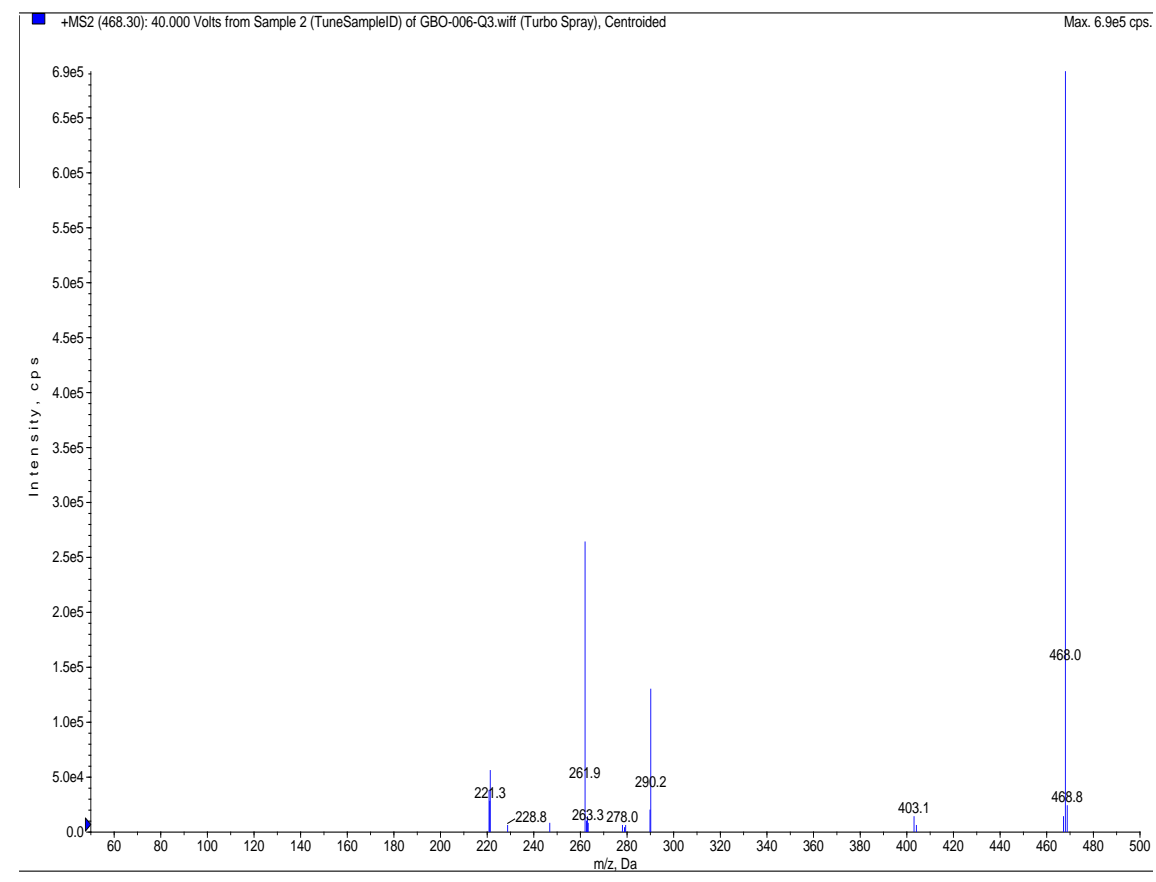

Figure 1. LC-MS spectra representing the product ion of GBO-006

\section{Pharmacokinetic analysis}

The pharmacokinetic parameters were obtained by fitting the plasma concentration-time data to a noncompartmental model by using Phoenix WinNonlin-v6.3.0.395; (Pharsight, Mountain view, CA). The maximum plasma concentration $\left(C_{\max }\right)$ and the time to reach the same $\left(T_{\max }\right)$ were determined by visually inspecting the profiles of plasma drug levels versus time. The half-life of plasma drug elimination $\left(t_{1 / 2}\right)$ was the ratio of 0.693 to the slope obtained by log-linear regression of the terminal phase of the drug plasma profile. The area under the concentration-time curve to terminal time $A \cup C_{0-t}$ ), (area under the concentration-time curve to infinite time $\left(A \cup C_{0-\infty}\right)$ and the mean residence time (MRT) were also evaluated. AUCt was calculated by the linear/log trapezoidal rule. Other pharmacokinetic variables, including the total plasma clearance (CL), steady-state volume of distribution (Vss), and oral bioavailability (\%F) were also calculated.

\section{Xenograft study}

All animal studies were performed according to the guidelines and approval of the appropriate Animal Care Committees. Female SCID beige mice 4-6 weeks of age were purchased from Taconic laboratories (Vivo biotech, Hyderabad, India) and housed in a pathogen-free environment under controlled conditions 
of light and humidity and allowed free access to food and water. Tumors were developed from MDA-MB231 cells inoculated subcutaneously (SC) into each mouse as previously described [10]. MDA-MB-231 cells were grown in RPMI $1640 \mathrm{w} / 10 \% \mathrm{FBS}, 2 \% \mathrm{P} / \mathrm{S}, 1.25 \%$ L-glut, and $1 \%$ sodium pyruvate to 80 \% confluency. Cells were trypsinized with $0.25 \%$ trypsin for 3-5 minutes, washed and suspended at 100 million cells per $\mathrm{ml}$. Animals received 5 million cells in matrigel (1:1 ratio of media and matrigel) and injected subcutaneously at the flank. Tumors were measured three times a week with vernier calipers and tumor volume measured using the formula length $\mathrm{x}$ width $2 / 2$. Treatment was initiated when the tumors reached an average volume of $100 \mathrm{~mm}^{3}$. One group was dosed with the formulation $\{(20 \% \mathrm{v} / \mathrm{v} \mathrm{DMSO}+40 \% \mathrm{w} / \mathrm{v}$ PEG $400+10 \% \mathrm{w} / \mathrm{v}$ Solutol $+30 \% \mathrm{v} / \mathrm{v}$ citrate buffer $(100 \mathrm{mM})\}$ with the dose volume of $10 \mathrm{ml} / \mathrm{kg}$ as a vehicle control, whereas the two other groups were dosed via intraperitoneal route with 30 and 75/mg/kg GBO-006. All dosing were done once daily (qd) for 24 days. Animal body weights were taken every alternate day, and they were monitored for general health status and any possible signs of treatment related toxicity.

\section{Results}

\section{Development of formulation of GBO-006}

Various percentage compositions of water soluble organic cosolvents, surfactants were evaluated for an optimized GBO-006 formulation (Table 1). GBO-006 concentrations in these formulations were kept fixed at $10 \mathrm{mg} / \mathrm{mL}$. Among these formulations (\#A-K), GBO-006 was initially dissolved and subsequently exhibited various degrees of precipitation after $24 \mathrm{~h}$ storage at room temperature. However, formulation \#L with $20 \%$ DMSO, $40 \%$ PEG 400, $30 \%$ of $100 \mathrm{mM}$ citrate buffer $(\mathrm{pH} \mathrm{3.0)}$ and $10 \%$ solutol displayed clear solutions without any visual precipitation of the drug even after 2 weeks of storage. Therefore, this formulation was selected for in vivo pharmacokinetic and efficacy studies.

Table 1. Formulation trails for $\mathrm{GBO}-006$ at $10 \mathrm{mg} / \mathrm{mL}$ by solvation strategy using co-solvents and surfactants

\begin{tabular}{|c|c|c|}
\hline Formula & Vehicle composition & Appearance at CRT \\
\hline$A$ & $\begin{array}{l}20 \% \text { v/v NMP }+20 \% \text { v/v Ethanol }+20 \% \text { v/v PEG } 400+10 \% \mathrm{w} / \mathrm{v} \text { TPGS }+1 \% \mathrm{w} / \mathrm{v} \text { Poloxamer } \\
188+\text { purified water q.s. }\end{array}$ & Precipitation after $8 \mathrm{~h}$ \\
\hline B & $\begin{array}{l}20 \% \text { v/v NMP }+20 \% \mathrm{w} / \mathrm{v} \text { Glycerin+ } 20 \% \mathrm{v} / \mathrm{v} \text { PEG } 400+10 \% \mathrm{w} / \mathrm{v} \text { solutol Hs } 15+10 \% \mathrm{w} / \mathrm{v} \\
\text { poloxamer } 188+\text { purified water q.s. }\end{array}$ & Precipitation after $48 \mathrm{~h}$ \\
\hline C & $\begin{array}{l}20 \% \text { v/v NMP }+20 \% \text { v/v Ethanol+ } 20 \% \text { v/v PEG } 400+10 \% \mathrm{w} / \mathrm{v} \text { solutol Hs } 15+10 \% \mathrm{w} / \mathrm{v} \\
\text { TPGS + purified water q.s. }\end{array}$ & Precipitation after $48 \mathrm{~h}$ \\
\hline D & $\begin{array}{l}20 \% \text { v/v NMP }+20 \% \text { w/v Glycerin+ } 20 \% \text { v/v Ethanol }+10 \% \mathrm{w} / \mathrm{v} \text { TPGS }+10 \% \mathrm{w} / \mathrm{v} \text { Poloxamer } \\
188+\text { purified water q.s. }\end{array}$ & Precipitation after $12 \mathrm{~h}$ \\
\hline $\mathrm{F}$ & $\begin{array}{l}20 \% \text { v/v NMP }+10 \% \text { v/v DMSO + 30\% v/v PEG } 400+20 \% \text { w/v Cremophor EL + + Purified } \\
\text { water q.s }\end{array}$ & Precipitation after $24 \mathrm{~h}$ \\
\hline G & $\begin{array}{l}20 \% \text { v/v NMP + 10\% v/v DMSO + 30\% v/v PEG } 400+10 \% \text { w/v Solutol HS } 15++ \text { Purified } \\
\text { water q.s }\end{array}$ & Precipitation after $48 \mathrm{~h}$ \\
\hline $\mathrm{H}$ & $20 \%$ v/v NMP + 10\% v/v DMSO + 30\% v/v PEG $400+20 \%$ w/v TPGS + Purified water q.s & Precipitation after $48 \mathrm{~h}$ \\
\hline I & $\begin{array}{l}20 \% \text { v/v NMP }+10 \% \text { v/v DMSO + 30\% v/v PEG } 400+20 \% \text { w/v Poloxamer } 188+\text { Purified } \\
\text { water q.s }\end{array}$ & Precipitation after $48 \mathrm{~h}$ \\
\hline $\mathrm{J}$ & $20 \%$ v/v NMP $+20 \%$ v/v DMSO $+30 \%$ v/v PEG $400+20 \%$ v/v Labrasol + Purified water q.s & Precipitation after $72 \mathrm{~h}$ \\
\hline K & $20 \% \mathrm{v} / \mathrm{v}$ DMSO $+30 \% \mathrm{w} / \mathrm{v}$ PEG $400+10 \% \mathrm{w} / \mathrm{v}$ Solutol $+30 \% \mathrm{v} / \mathrm{v}$ citrate buffer $(100 \mathrm{mM})$ & $\begin{array}{lll}\begin{array}{l}\text { Precipitation after } 1 \\
\text { week }\end{array} & \\
\end{array}$ \\
\hline $\mathrm{L}$ & $20 \% \mathrm{v} / \mathrm{v}$ DMSO $+40 \% \mathrm{w} / \mathrm{v}$ PEG $400+10 \% \mathrm{w} / \mathrm{v}$ Solutol $+30 \% \mathrm{v} / \mathrm{v}$ citrate buffer $(100 \mathrm{mM})$ & $\begin{array}{l}\text { No visual precipitation up } \\
\text { to } 2 \text { weeks }\end{array}$ \\
\hline
\end{tabular}

We observed that the solubility of GBO-006 in DMSO, a pharmaceutically acceptable strong solubilizing agent, was quite high. Hence, DMSO was chosen as the solubilizing agent in our formulation. The PEG 400 (at $40 \% \mathrm{v} / \mathrm{v}$ ) was found to be a suitable additive in the formulation, as we observed a clear solution of high miscibility and compatibility with water. However, at a lower concentration of 10-30 \% v/v, PEG 400 was found to be insufficient to prevent precipitation of free GBO-006, observed after $24 \mathrm{~h}$. Therefore, PEG 400 was fixed at a concentration of $40 \% \mathrm{v} / \mathrm{v}$. 
Among the different percentage compositions of the nonionic surfactants considered, including Tween 80 , cremophor, labrasol, transcutol and solutol, the latter surfactant was picked as an ingredient in the optimal formulation at a concentration of $10 \% \mathrm{w} / \mathrm{v}$. This was purely based on the solubility, clarity and miscibility of solutol at this concentration with the rest of the additives in the formulation. It was also found that a percentage concentration of $5 \% \mathrm{w} / \mathrm{v}$ is insufficient to prevent the precipitation of the free GBO-006. Hence, we decided to optimize the formulation with at a percentage concentration of $10 \% \mathrm{w} / \mathrm{v}$.

\section{LC-MS/MS analytical method}

No interfering peaks were observed in blank plasma chromatograms at GBO-006 retention time (Figure 2). The retention times for GBO-006 and internal standard were 1.58 and $1.80 \mathrm{~min}$, respectively. The calibration curves and linearity was determined using weighted $\left(1 / \mathrm{x}^{2}\right)$ linear regression analysis in the following ranges of 1 to $1000 \mathrm{ng} / \mathrm{mL}$ in rat, mouse and dog plasma. The correlation coefficients were > 0.995 for calibration curves. The batch was accepted once the low, medium and high quality control (QC) samples and standard samples met the acceptance criteria.

\section{Pharmacokinetics in rats}

A plasma concentration and time profile of GBO-006 obtained is shown in Figure 3 and corresponding pharmacokinetic parameters are shown in Table 2. After intravenous bolus injection, the plasma concentrations declined by $99 \%$ over the first $4 \mathrm{~h}$. GBO-006 showed moderate clearance (equivalent to $55 \%$ of rat hepatic blood flow) with half-life of $0.6 \mathrm{~h}$ and extra vascular distribution. It showed poor oral bioavailability.

\section{Pharmacokinetics in mice}

Following IV and PO administration in mouse, GBO-006 showed high clearance $(77 \mathrm{ml} / \mathrm{min} / \mathrm{kg}$, equivalent to $85 \%$ of mouse hepatic blood flow), short terminal half-life $(0.5 \mathrm{~h})$ and poor oral bioavailability (Table 3). Similar to rat, after intravenous bolus injection the plasma concentrations declined by $99 \%$ over the first $4 \mathrm{~h}$ (Figure 4). Dose dependent pharmacokinetic parameters following IP administration at three different dose levels are listed in Table 4. As the dose increased from 1 to $3,7.5$ and 10 fold, the area under the curve of plasma concentration versus time profile increased 1 to, 5,8 and 10 fold. As demonstrated in Figure 5, GBO-006 plasma concentrations escalates as the dose increased, thus displaying linear pharmacokinetics. 
(A)

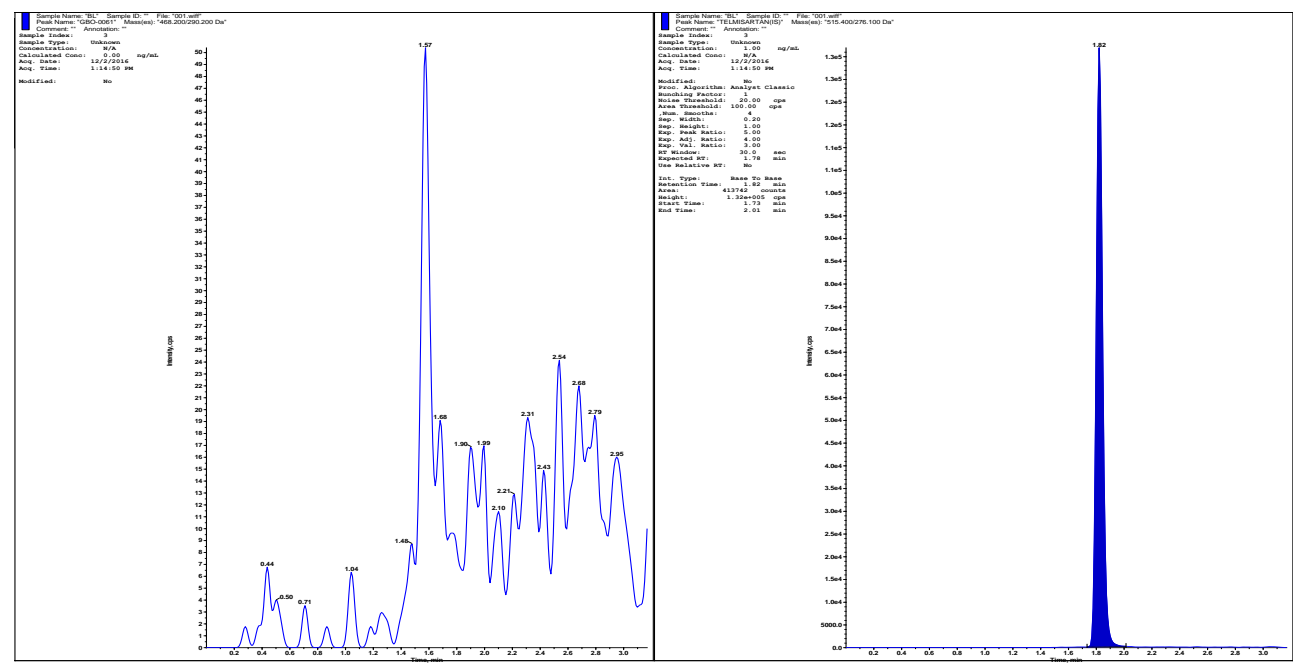

(B)

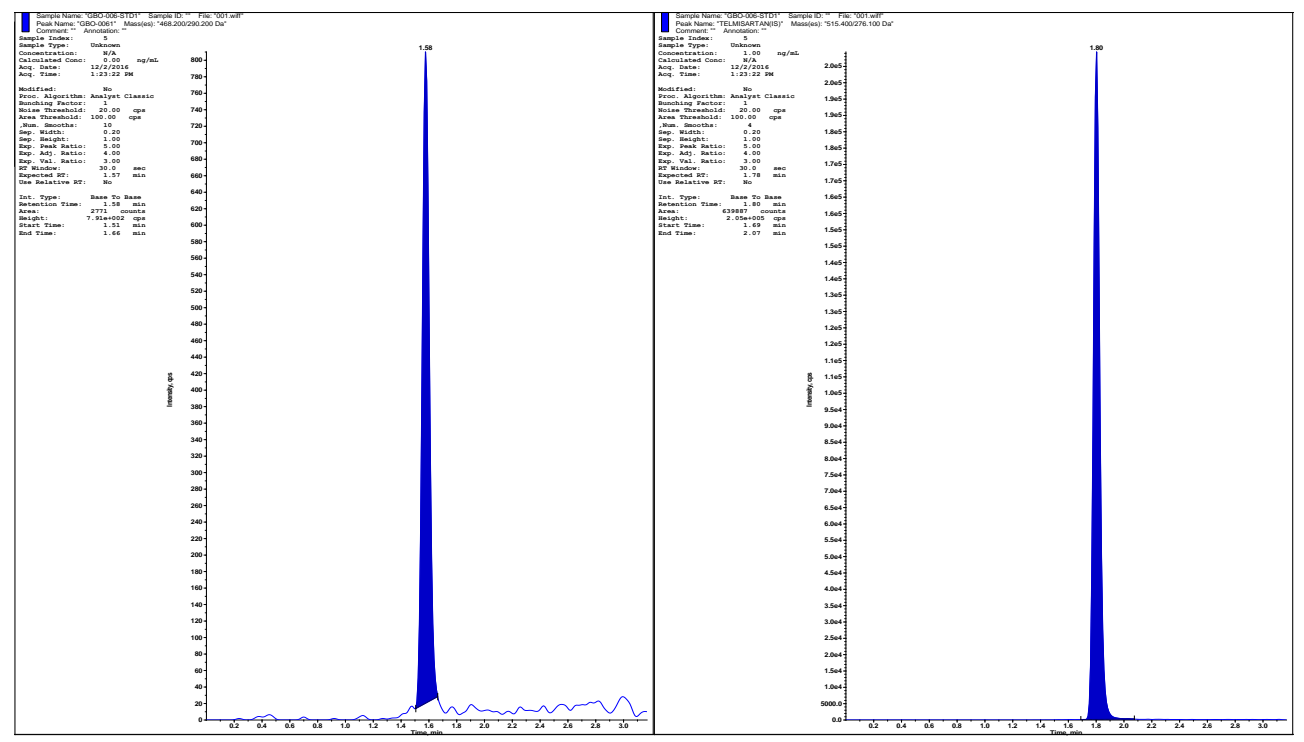

Figure 2. Representative MRM chromatograms of GBO-006 obtained from blank plasma sample (A) and calibration standard plasma sample of $1 \mathrm{ng} / \mathrm{mL}$, LLOQ (B).

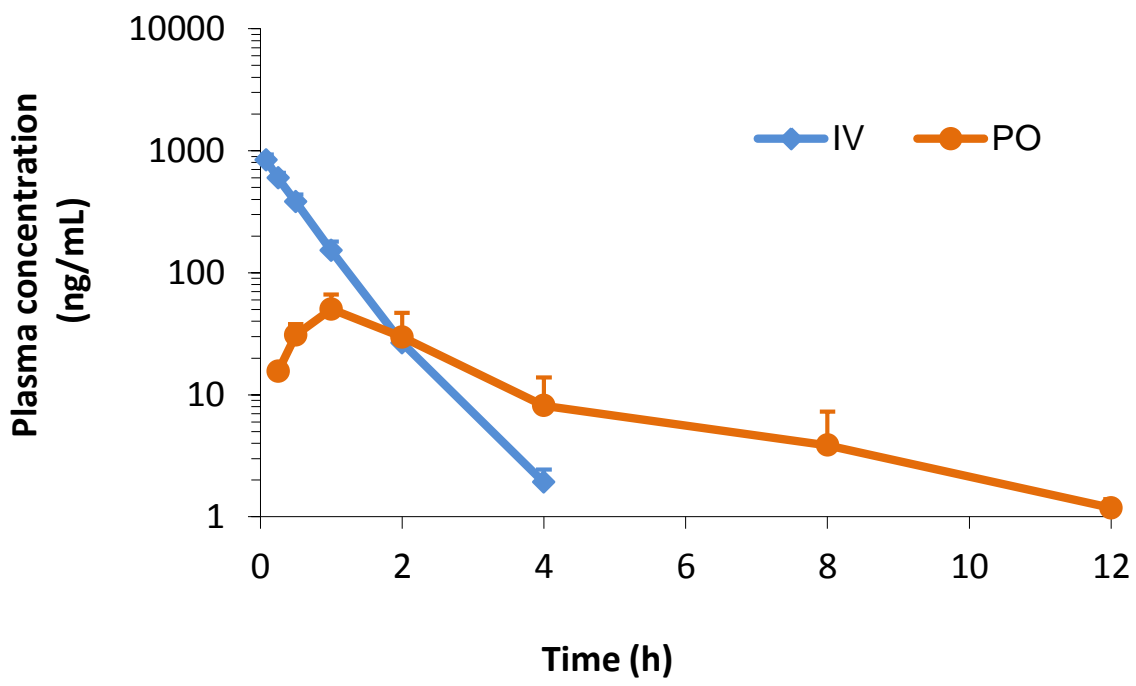

Figure 3. Mean plasma concentration vs. time curve of GBO-006 following its intravenous and oral administration in male sprague dawley rat. Each point $(n=3)$ represents the mean \pm SD. 
Table 2. Pharmacokinetic parameters of GBO-006 following its intravenous and oral route administration in male Sprague Dawley rat. Data are expressed as mean \pm SD in three rats.

\begin{tabular}{|c|c|c|}
\hline & IV & PO \\
\hline Dose $(\mathrm{mg} / \mathrm{kg})$ & 1 & 5 \\
\hline $\boldsymbol{C}_{\max }(\mathrm{ng} / \mathrm{mL})$ & - & 22 \\
\hline $\boldsymbol{T}_{\max }(\mathrm{h})$ & - & 1 \\
\hline $\mathrm{AUC}_{\mathbf{0 - 2 4 h}}(\mathrm{ng} \mathrm{h} / \mathrm{mL})$ & 535 & 87 \\
\hline $\mathrm{DNAUC}$ & 535 & 17 \\
\hline $\mathrm{CL}(\mathrm{mL} / \mathrm{min} / \mathrm{Kg})$ & 30 & - \\
\hline $\boldsymbol{t}_{\text {half }}(\mathrm{h})$ & 0.6 & - \\
\hline $\boldsymbol{V}_{\text {dss }}(\mathrm{L} / \mathrm{kg})$ & 1.5 & - \\
\hline MRT last (h) $^{\text {Bioavailability (\%F) }}$ & 0.5 & - \\
\hline
\end{tabular}

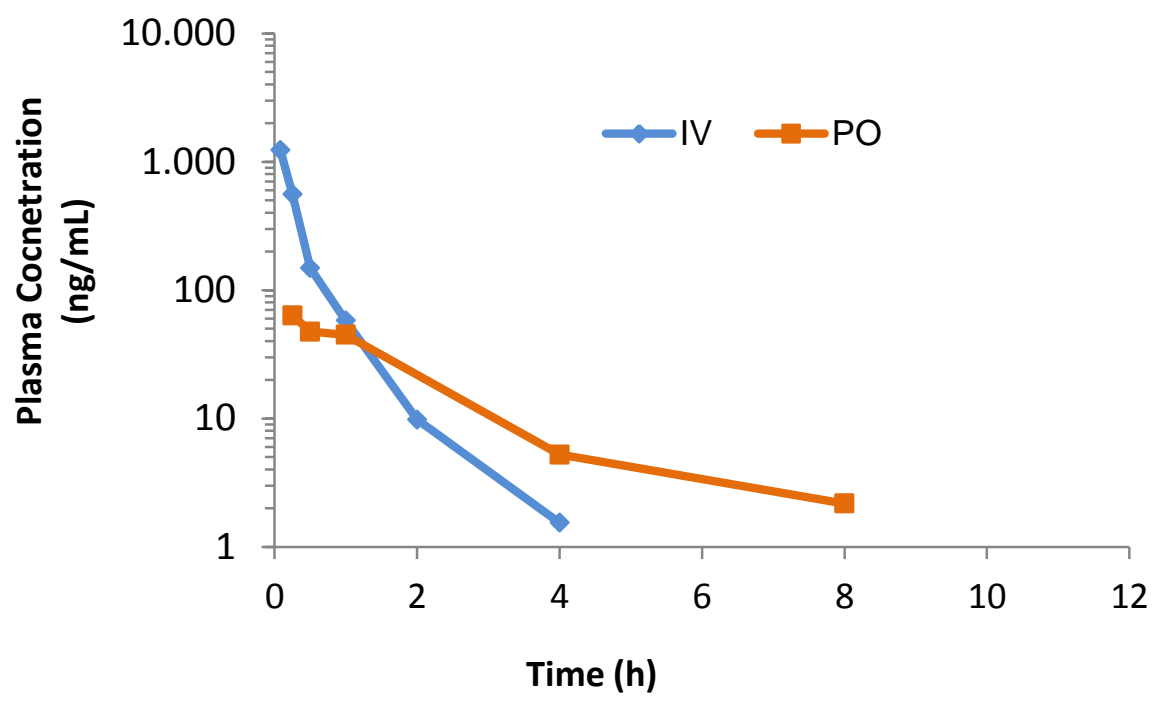

Figure 4. Mean plasma concentration vs. time following intravenous and oral administration of GBO-006 in male swiss albino mice.

Table 3. Pharmacokinetic parameters of GBO-006 following its intravenous and oral route of administration in mouse.

\begin{tabular}{|c|c|c|}
\hline & IV & PO \\
\hline Dose $(\mathrm{mg} / \mathrm{kg})$ & 2 & 5 \\
\hline $\mathrm{CL}(\mathrm{mL} / \mathrm{min} / \mathrm{Kg})$ & 77 & - \\
\hline $\boldsymbol{t}_{\text {half }}(\mathrm{h})$ & 0.5 & - \\
\hline $\boldsymbol{V}_{\text {dss }}(\mathrm{L} / \mathrm{kg})$ & 1.7 & - \\
\hline $\mathrm{MRT}$ last (h) & 0.4 & - \\
\hline $\boldsymbol{C}_{\max , \mathrm{PO}(\mathrm{ng} / \mathrm{mL})}$ & - & 64 \\
\hline $\boldsymbol{T}_{\max , \mathrm{PO}(\mathrm{h})}$ & - & 0.25 \\
\hline AUC $_{\text {0-24h }}$ (ng h /mL), IV/PO & 431 & 25 \\
\hline Bioavailability (\%F) & \multicolumn{2}{|c}{} \\
\hline
\end{tabular}


Table 4. Pharmacokinetic parameters of GBO-006 following intraperitoneal administration in swiss albino mouse at $10,30,75,100 \mathrm{mg} / \mathrm{kg}$

\begin{tabular}{|c|c|c|c|c|}
\hline Dose (mg/kg) & 10 & 30 & 75 & 100 \\
\hline $\begin{array}{l}\text { Formulation strength } \\
\qquad(\mathrm{mg} / \mathrm{mL})\end{array}$ & 1 & 3 & 7.5 & 10 \\
\hline$C_{\max }(\mathrm{ng} / \mathrm{mL})$ & 952 & 1413 & 1354 & 1652 \\
\hline$T_{\max }(\mathrm{h})$ & 0.25 & 4 & 0.25 & 8 \\
\hline$A \cup C_{0-24 h,}(\mathrm{ng} / \mathrm{mL} h)$ & 2451 & 13530 & 20177 & 25592 \\
\hline$A U C_{0-\infty}(n g / m L ~ h)$ & 2531 & 13807 & 27067 & 33744 \\
\hline $\begin{array}{l}\text { Dose normalized } \\
\mathrm{AUC}_{0-\infty}(\mathrm{ng} / \mathrm{mL} \mathrm{h})\end{array}$ & 253 & 460 & 360 & 337 \\
\hline
\end{tabular}

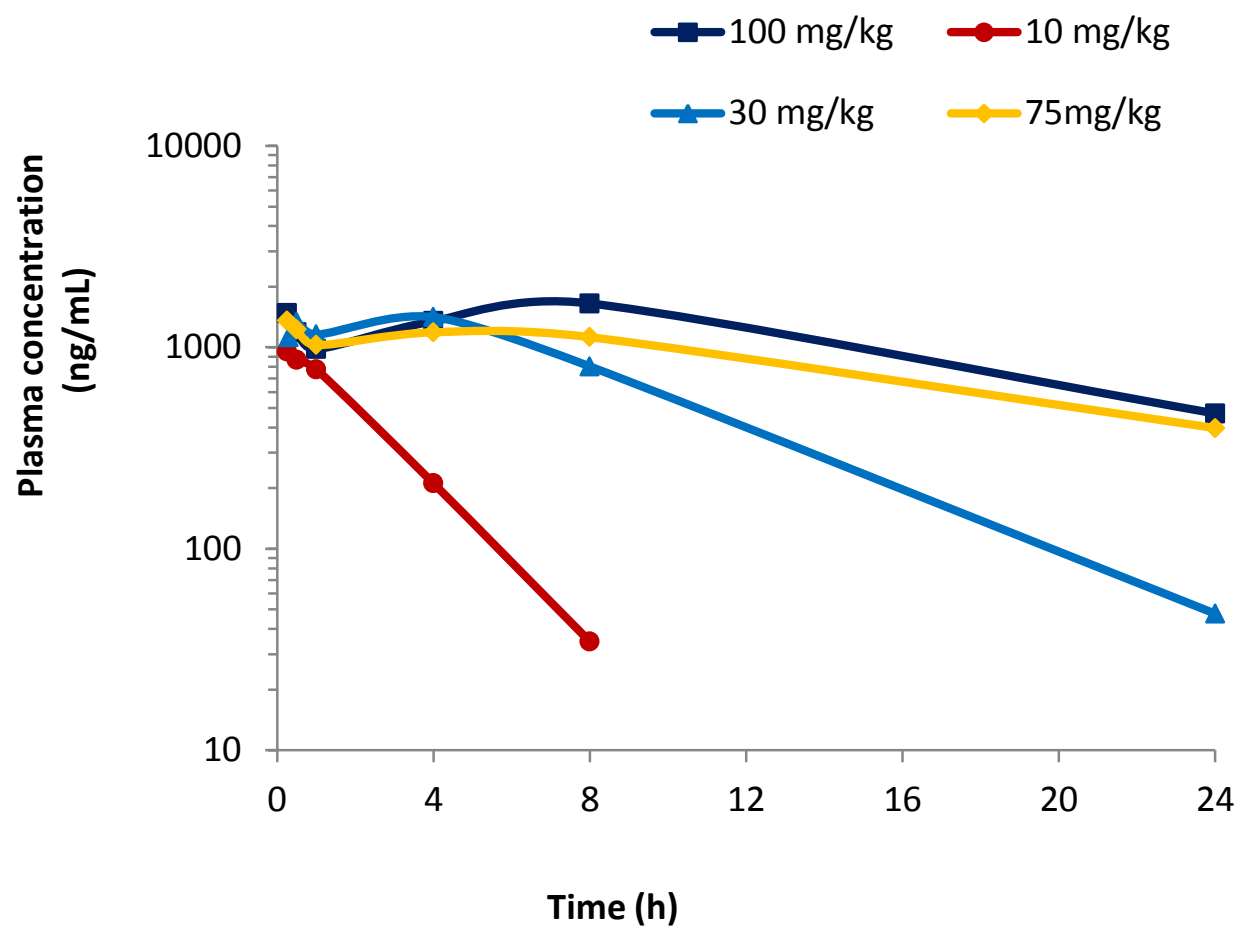

Figure 5. Mean plasma concentration vs. time following intraperitoneal administration of GBO-006 at different doses in swiss albino mice.

\section{Pharmacokinetics in dogs}

A plasma concentration and time profile of GBO-006 obtained in dog is shown in Figure 6 and corresponding pharmacokinetic parameters are shown in Table 5. Similar to results in mice, GBO-006 showed high clearance $(47 \mathrm{ml} / \mathrm{min} / \mathrm{kg}$, more than dog hepatic blood flow) and short plasma elimination half-life $(0.7 \mathrm{~h})$ in dogs indicating that the compound is rapidly eliminated from the body. The volume of distribution of $2.4 \mathrm{~L} / \mathrm{kg}$ provides significant distribution into extra vascular space. Poor bioavailability (6 \%) after PO dosing showed that the compound did not show any absorption through gastrointestinal tract. 


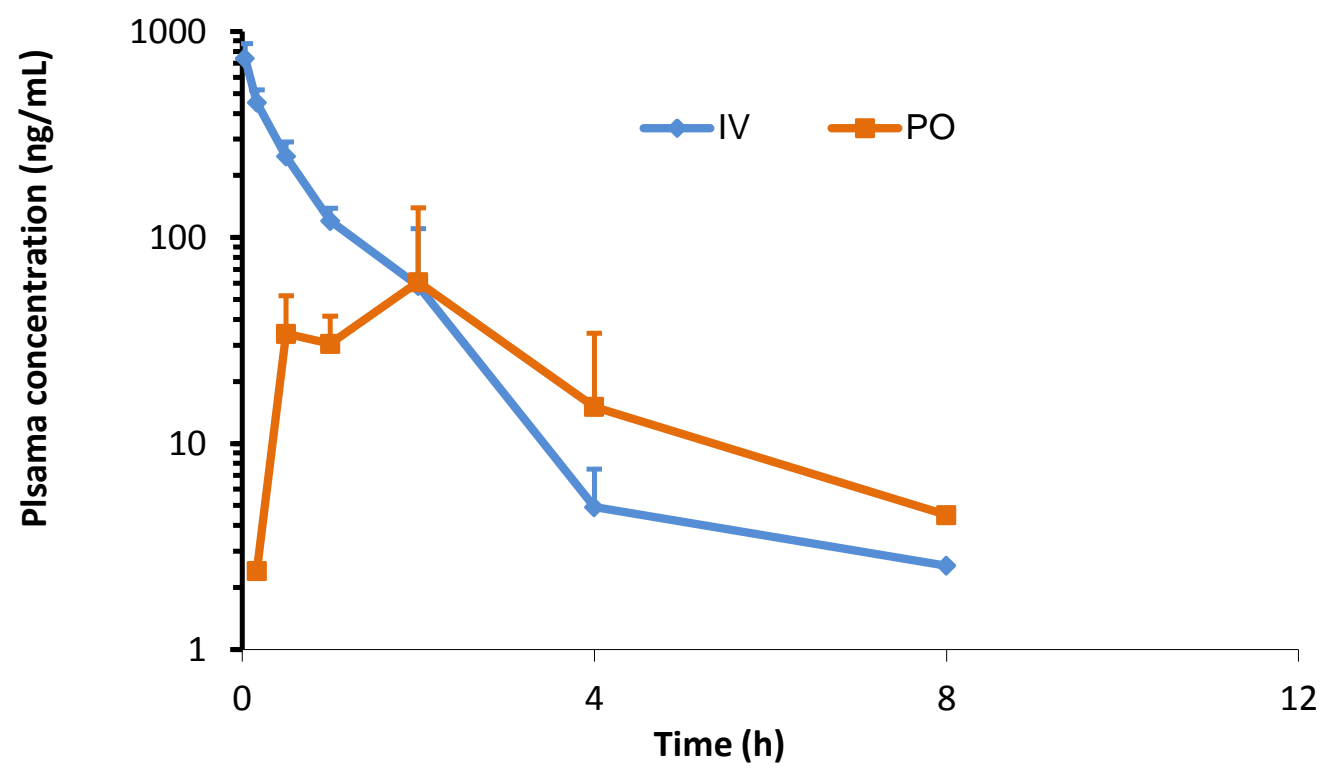

Figure 6. Mean plasma concentration vs. time following intravenous and oral administration of GBO-006 in male beagle dog. Each point $(n=3)$ represents the mean \pm SD.

Table 5. Pharmacokinetic parameters of GBO-006 following its intravenous and oral route administration in beagle dog. Data are expressed as mean \pm SD in three dogs.

\begin{tabular}{|c|c|c|}
\hline & IV & PO \\
\hline Dose (mg/kg) & 1 & 5 \\
\hline $\mathrm{CL}(\mathrm{mL} / \mathrm{min} / \mathrm{Kg})$ & 47 & - \\
\hline$t_{\text {half }}(\mathrm{h})$ & 0.7 & - \\
\hline$V_{\mathrm{dss}}(\mathrm{L} / \mathrm{kg})$ & 2.4 & - \\
\hline MRT last (h) & 0.8 & - \\
\hline$C_{\max }, \mathrm{PO}(\mathrm{ng} / \mathrm{mL})$ & - & 70 \\
\hline$T_{\max }, \mathrm{PO}(\mathrm{h})$ & - & 0.8 \\
\hline$A U C_{0-24 h}(\mathrm{ng} \mathrm{h} / \mathrm{mL})$, & 440 & 160 \\
\hline Bioavailability (\%F) & \multicolumn{2}{|c|}{6} \\
\hline
\end{tabular}

\section{Xenograft model}

GBO-006 reduced tumor volume by 52 and $58 \%$ at doses of 30 and $75 \mathrm{mg} / \mathrm{kg}$ respectively (Figure 7). The tumor growth inhibition at $30 \mathrm{mg} / \mathrm{kg}$ and $75 \mathrm{mg} / \mathrm{kg}$ dose was almost similar. The lack of dose dependent efficacy was not known at this movement. No statistically significant weight loss was found upon completion of the experiment in the treated groups compared to the vehicle group. There were no abnormalities found in liver, heart, lungs and kidneys suggesting that the compound was well tolerated up to $75 \mathrm{mg} / \mathrm{kg}$. 


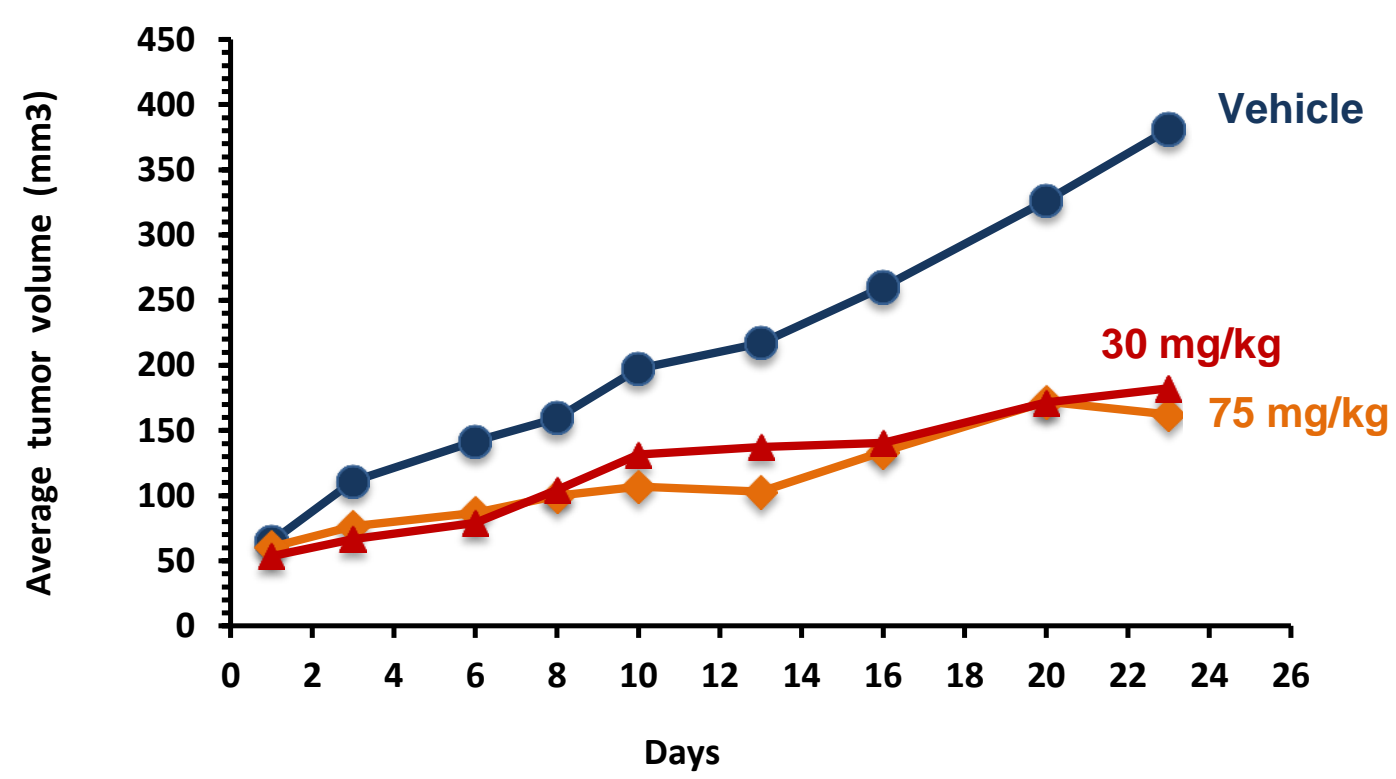

Figure 7. SCID mice bearing established tumors $\left(100 \mathrm{~mm}^{3}\right)$ from MDA-MB-231 cells were treated with GBO006 at $30 \mathrm{mg} / \mathrm{kg}$ (triangle), $75 \mathrm{mg} / \mathrm{kg}$ (Square), or vehicle (circle) for approximately 24 days. Serial tumor volumes $\left(\mathrm{mm}^{3}\right)$ were measured at the indicated days. Each data point represents the mean tumor volume of 8 tumors.

\section{Discussion}

GBO-006 is a small PLK2 selective kinase inhibitor which showed cytotoxicity against the entire panel of 16 tumor cell lines, with little or no cytotoxicity towards normal cells. Kinase inhibition assays against a panel of 285 kinases revealed that this compound had a remarkable specificity towards PLK2/Snk, a kinase involved in centrosome duplication and mitotic progression [11-13]. Most importantly, PLK2 has recently been implicated as one of the kinases that links cellular metabolism to cell cycle. Mitochondrial dysfunction with increased dependence on glycolysis is frequently observed in cancer cells (known as the Warburg effect) and identification of pathways that promote cell survival under conditions of mitochondrial dysfunction has therapeutic implications [14]. Intraperitoneal alternate day dosing of GBO-006 using $100 \%$ DMSO as formulation caused significant tumor regression in xenograft models, demonstrating proof of concept of PLK2 inhibition in vivo. These studies necessitated the need to develop a formulation for pharmacokinetic and efficacy studies. The present communication describes the development of preclinical formulation to characterize the pharmacokinetic properties and efficacy of GBO-006 in xenograft models to determine the degree of inhibition of PLK2 that is required for inhibition of tumor growth and assess how concentrations are related to antitumor activity of the compound and to evaluate the validity of using PBMN as surrogates.

GBO-006 possesses challenging physicochemical and biopharmaceutical properties like poor solubility in aqueous media, low permeability and a crystalline nature. The poor solubility of GBO-006 in non-aqueous media including lipids \& oils, limited any further usage of lipid-based technologies. GBO-006 was found to melt with degradation at very high temperatures $\left(\sim 346{ }^{\circ} \mathrm{C}\right)$, which limited the usage of any amorphous based strategies. In order to understand the solubility, initial screening was conducted in different concentrations and combinations of cosolvents and surfactants. Among the various combinations and various solvent compositions tried in our laboratory, a cosolvent system was chosen consisting of DMSO, PEG 400, solutol and $100 \mathrm{mM}$ citrate buffer at 20:40:10:30 (v/v/v/v) ratios. This system showed $10 \mathrm{mg} / \mathrm{mL}$ drug solubility without drug precipitation up to storage of $24 \mathrm{~h}$. Thus, this formulation was selected for in 
vivo pharmacokinetic and efficacy evaluations.

DMSO and PEG 400 are the major pharmaceutical cosolvents with strong solubilizing properties and widely used in oral and parenteral formulations. DMSO is a water miscible polar aprotic solvent with high interfacial activity as a drug solubilizer and a penetration enhancer [15]. It also belongs to the class of dipolar aprotic solvents which includes dimethylformamide and dimethylacetamide. The cosolvent approach is based on the fact that low aqueous solubility of drugs is due to great difference in polarity of the two components. Thus when a cosolvent having a polarity value less than that of water is added, the polarity difference between the drug and the water-co solvent system reduces thereby increase the solubility of drug [16].

GBO-006 pharmacokinetic studies provided an overview of the absorption and disposition behavior in animal models. GBO-006 showed very poor oral bioavailability (2-6\%) across mice, rats and dogs (Figures 3, 4 and 6). Potential causes for the low oral bioavailability could be due to metabolism in the gut wall, and first-pass metabolism in the liver [17-19]. Following intravenous dosing to mice, rats and dogs, GBO-006 is rapidly eliminated from plasma within the first several hours with half-life estimates ranging from 0.5 to 0.7 h over this period. Overall, GBO-006 pharmacokinetics was comparable across the three species tested. Clearance, the critical connection between the administered dose and drug exposure (AUC), was very high (which is more than hepatic blood volume) and consistent among mouse and dog. Single day dose escalation study by intraperitoneal route demonstrated the dose proportional increase in AUC and $C_{\max }$, thus displaying linear pharmacokinetics. Since linear exposure was observed in mice, 30 and $75 \mathrm{mg} / \mathrm{kg}$ were selected for xenograft study, where $30 \mathrm{mg} / \mathrm{kg}$ dose showed greater than $50 \%$ tumor regression. Further studies are required to compare the efficacy dosage in mice to adverse dosage effects in rat, for non-clinical risk assessment. Current efforts are focusing on formulation studies that would enable us to carry out GLP tox at higher doses of GBO-006.

\section{Acknowledgements}

We gratefully acknowledge the thoughtful suggestions and constructive criticism from E. P. Reddy was supported by CA158209.

\section{Conflict of Interest}

The authors declare that they have no conflict of interest.

\section{References}

[1] N. Takai, R. Hamanaka, J. Yoshimatsu, I. Miyakawa, Oncogene 24 (2005) 287-291.

[2] P. Chopra, G. Sethi, S.G. Dastidar, A. Ray, Expert Opin. Investig. Drugs 19 (2010) 27-43.

[3] E.M. Matthew, L.S. Hart, A. Astrinidis, A. Navaraj, N.G. Dolloff, D.T. Dicker, E.P. Henske, W.S. ElDeiry, Cell Cycle 8 (2009) 4168-4175.

[4] T.F. Burns, P. Fei, K.A. Scata, D.T. Dicker, W.S. El-Deiry, Mol. Cell Biol. 23 (2003) 5556-5571.

[5] S. Warnke, S. Kemmler, R.S. Hames, H.L. Tsai, U. Hoffmann-Rohrer, A.M. Fry, Curr. Biol. 14 (2004) 1200-1207.

[6] T. Lu, C.A. Laughton, S. Wang, T.D. Bradshaw, Mol. Pharmacol. 87 (2015) 18-30.

[7] J.P. Zhang, J. Huang, C. Liu, X.F. Lu, B.X. Wu, L. Zhao, N. Lu, Q.L. Guo, Z.Y. Li, C. Jiang, Chinese Chemical Letters 25 (2014) 1025-1028.

[8] S. Cockerill, C. Stubberfield, J. Stables, M. Carter, S. Guntrip, K. Smith, S. McKeown, R. Shaw, P. Topley, L. Thomsen, K. Affleck, A. Jowett, D. Hayes, M. Willson, P. Woollard, D. Spalding, Bioorganic \& Medicinal Chemistry Letters 11 (2001) 1401-1405. 
[9] M.V. Reddy, B. Akula, S. Jatiani, R. Vasquez-Del Carpio, V.K. Billa, M.R. Mallireddigari, S.C. Cosenza, D.R. Venkata Subbaiah, E.V. Bharathi, V.R. Pallela, P. Ramkumar, R. Jain, A.K. Aggarwal, E.P. Reddy, Bioorg. Med. Chem. 24 (2016) 521-544.

[10] M.K. You, M.S. Kim, K.S. Jeong, E. Kim, Y.J. Kim, H.A. Kim, Nutrition Research and Practice 10 (2016) 139-147.

[11] V. Archambault, D.M. Glover, Nat. Rev. Mol. Cell Biol. 10 (2009) 265-275.

[12] K. Strebhardt, Nat. Rev. Drug Discov. 9 (2010) 643-6600.

[13] O. Cizmecioglu, A. Krause, R. Bahtz, L. Ehret, N. Malek, I. Hoffmann. J. Cell Sci. 125 (2012) 981-992.

[14] T. Matsumoto, P.Y. Wang, W. Ma, H.J. Sung, S. Matoba, P.M. Hwang, Proc. Natl. Acad. Sci. U S A. 106 (2009) 14542-14546.

[15] P.K. Gupta, The Science and Practice of Pharmacy (21st edition), Remington, Philadelphia, USA, 2005.

[16] M. Sun, L. Si, X. Zhai, Z. Fan, Y. Ma, et al., Drug Dev. Ind. Pharm. 37 (2011) 986-994.

[17] B.S. Shin, S.D.Yoo, T.H. Kim, Drug Metab. Dispos. 42 (2014) 974-982.

[18] J.M. Smoliga, O. Blanchard, Molecules 19 (2014) 17154-17172.

[19] D.I. Draganov, D.A. Markham, D. Beyer, et.al., Toxicology 333 (2015) 168-178.

\section{Abbreviations Definitions}

$\begin{array}{ll}\text { DMSO } & \text { Dimethyl sulfoxide } \\ \text { DMA } & \mathrm{N}, \mathrm{N} \text {-Dimethyl acetamide } \\ \text { LLOQ } & \text { Lower limit of quantitation } \\ \text { NMP } & \text { N-methyl pyrrolidine } \\ \text { PBMN } & \text { Peripheral blood mononuclear cells } \\ \text { PEG } & \text { Polyethylene glycol } \\ \text { TPGS D } & \text { Alpha tocopheryl polyethylene glycol } 1000 \text { succinate }\end{array}$

\footnotetext{
(C)2016 by the authors; licensee IAPC, Zagreb, Croatia. This article is an open-access article distributed under the terms and conditions of the Creative Commons Attribution license (http://creativecommons.org/licenses/by/3.0/) (cc) ) EY
} 